\title{
Possible Anti-oxidant Effect of Lamotrigine in Nucleus Accumbens of Mice Exposed to Picrotoxin
}

\author{
Sahar Mohamed Kamal ${ }^{*}$
}

Associate Professor, Department of Pharmacology, University of Ain-Shams, Egypt

\begin{abstract}
The present study was performed to investigate whether or not lamotrigine (an anti-epileptic drug by sodiumchannel blockade and also increases gamma-aminobutyric acid [GABA]) could increase some anti-oxidant markers in the nucleus accumbens of mice exposed to picrotoxin as a model simulating convulsions in human. The results indicated that the anti-epileptic drug significantly increased the activities of glutathione peroxidase and catalase enzymes in nucleus accumbens homogenates as well as the contents of superoxide dismutase enzyme in red blood cells (RBCs) lysates in this model of convulsion. In addition the tested drug significantly decreased the level of the lipid peroxidation expressed as thiobarbituric acid-reactive substance (TBARS) in nucleus accumbens homogenates. So, the present study showed that the tested antiepileptic drug could potentiate its anticonvulsant activity via a possible anti-oxidant activity.
\end{abstract}

Keywords: Lamotrigine; Picrotoxin; Antioxidant; Mice

\section{Introduction}

Oxidative stress is a common mechanism in the causation of many diseases including organ damage [1]. The increase in production of Reactive Oxygen Species (ROS) is found to be contributed to nerve injury $[1,2]$. In normal neuron, ROS production is tightly regulated. The free radical superoxide is generated by mitochondrial electron transfer chain when nicotinamide adenine dinucleotide (NADH) is oxidised to $\mathrm{NAD}^{+}$. Superoxide produced in various diseases rapidly combines with $\mathrm{NO}$ and the formed peroxynitrite causes protein nitration or nitrosylation, lipid peroxidation, DNA damage and cell death and has direct toxic effects on the nerve tissue leading to neuronal damage, neuropathic pain and convulsions $[3,4]$. Mitochondria in neuron is sensitive to oxidative damage-which results impaired energy regulatory function that leads to loss of neuronal function and the development of PDN [1]. Moreover, excess generation of mitochondrial ROS due to neuronal toxicity initiates a vicious circle by activating stress-sensitive pathways such as NF$\kappa \mathrm{B}$, p38 MAPK, Jak/STAT, PKC and pro-inflammatory cytokines that contribute to many complications $[5,6]$. In addition, there is an increase in the formation of potent oxidant peroxynitrite, which is formed by the combination of superoxide anion radical with nitric oxide and the formed peroxynitrite has been documented to play a key role in experimental and clinical neuropathy. Peroxynitrite causes nitration and nitrosylation of biomolecules including proteins, lipids, DNA and has a direct toxic effect on neurons leading to complications in the nervous systems $[4,7]$.

There is strong evidence supporting the correlation between oxidative stress and epilepsy. Free radicals are involved in the pathogenesis of various diseases including epilepsy [8]. Chemo convulsions, e.g. picrotoxin-induced convulsions, are followed by the generation of free radicals that cause lipid peroxidation, which may subsequently cause neurodegeneration observed in certain types of human epilepsy [9]. Therefore, a drug that reduces seizure activity should also lower TBARS (Thiobarbituric acid reactive substances) levels. Reduction of TBARS levels compared to those by chemoconvulsants alone would also give an indication of the additional neuroprotective and/or antioxidant properties of the drug [10].

Lamotrigine (Lamictal) is included in the phenyltriazine class. It is used as adjunctive therapy or monotherapy in adults with partial seizures with or without secondary generalization. Lamotrigine has been shown to act at voltage-sensitive sodium channels, stabilizing neural membranes and inhibiting the release of excitatory neural transmitter [11].

The nucleus accumbens (NAcc) (The pleasure center) is the studied brain area of tested mice. It is formed of a collection of neurons and considers being the main part of the ventral striatum. It is thought to play an important role in reward, pleasure, laughter, addiction, aggression, fear. However, no detectable experimental studies pointed to its possible role in pathogenesis and treatment of epilepsy [12].

The present study is performed to investigate whether or not lamotrigine, as an anti-epileptic drug, could increase or decrease some anti-oxidant markers in the nucleus accumbens (whose main neurotransmitter of its neurons is GABA) of mice exposed to picrotoxin as a model simulating convulsions in human.

\section{Materials and Methods}

\section{Drugs and chemicals}

Picrotoxin (PTX; Sigma-Aldrich Co, St Louis, MO), lamotrigine (Sigma-Aldrich, St. Louis, MO, USA) was dissolved in a mixture of $0.5 \%$ carboxymethylcellulose, $0.4 \%$ Tween $80,0.9 \%$ benzylic acid and saline and for measurement of superoxide dismutase enzyme from Randox Laboratories (Crumlin, UK). All other chemicals were obtained from Sigma Chemical Co (St Louis, MO).

${ }^{*}$ Corresponding author: Dr. Sahar Mohamed Kamal, Faculty of Medicine, Associate Professor, Department of Pharmacology, University of Ain Shams, Cairo - Egypt, Tel: 00202-24186992; E-mail: saharkamal2003@hotmail.com

Received February 11, 2013; Accepted March 21, 2013; Published March 24 2013

Citation: Kamal SM (2013) Possible Anti-oxidant Effect of Lamotrigine in Nucleus Accumbens of Mice Exposed to Picrotoxin. J Neurol Disord 1: 108. doi:10.4172/ 2329-6895.1000108

Copyright: (C) 2013 Kamal SM. This is an open-access article distributed under the terms of the Creative Commons Attribution License, which permits unrestricted use, distribution, and reproduction in any medium, provided the original author and source are credited. 


\section{Animals}

Albino mice (20-25 g) were divided into three groups with 12 mice each. They were housed in cages with a natural light-dark cycle and fed on a standard pellet diet and water ad libitum.

\section{A) Picrotoxin-induced convulsions}

All mice were given a single subcutaneous dose $(3.5 \mathrm{mg} / \mathrm{kg}$ body weight) of PTX either in the absence of any treatment (control group) or following administration of a single dose of the test drug (treated groups either by vehicles [group 2] or by lamotrigine [group 3]). Accordingly, the study comprised the following three groups:

1. Control group did not receive lamotrigine.

2. Control group did not receive lamotrigine, only its vehicles.

3. Lamotrigine-treated group: received lamotrigine dissolved in a mixture of $0.5 \%$ carboxymethylcellulose, $0.4 \%$ Tween $80,0.9 \%$ benzylic acid and saline [13] as a single dose of $20 \mathrm{mg} / \mathrm{kg}$ body weight intraperitoneal [14].

In the treated group, PTX was injected after a suitable latency corresponding to the time expected to reach a peak effect following administration of the respective test drug.

The latency of lamotrigine was estimated to be 1 hour after its intraperitoneal administration, as determined by the pilot study.

Immediately after administration of PTX, the animal was observed for 30 minutes. The onset of convulsive behavior as well as the nature and severity of convulsions were carefully recorded using the scoring system 1-7 as follows: hyperlocomotion or piloerection (erection of the skin hair), 1; stunning (immobile) or catatonic posture (assuming a fixed posture and inability to move), 2; clonic body tremors (a series of involuntary muscular contractions due to sudden stretching of the muscle), 3; prolonged clonic tremors, 4 ; tonic forelimb convulsions followed by clonus, 5 ; repetitive tonic (prolonged muscular contraction) forelimb convulsions followed by clonus, 6 ; and tonic extension of both forelimbs and hindlimbs followed by clonus, 7 ; a mean cumulative score was calculated for lamotrigine-treated group for comparisons and statistical analysis.

B) Exposure of tested groups to chronic restraint stress procedure followed by the antioxidant tests:

At the end of the PTX study for each group, the animals were returned to their cages to continue with the chronic restraint stress study.

Each mouse of the respective group was placed in a wire mesh restrainer 6 hours daily for 21 days. At the end of the restraint period, the mice were moved to their cages.

For the purpose of the antioxidant tests, the following three groups were classified as followed:

1. Control group did not receive lamotrigine.

2. Control group did not receive lamotrigine, only its vehicles.

3. Lamotrigine-treated group: received lamotrigine dissolved in a mixture of $0.5 \%$ carboxymethylcellulose, $0.4 \%$ Tween $80,0.9 \%$ benzylic acid and saline [13] as a single dose of $20 \mathrm{mg} / \mathrm{kg}$ body weight intraperitoneal [14].

\section{Superoxide dismutase in erythrocyte lysates [15]}

At the end of 21 days of exposure to chronic restraint, blood samples were collected from the rabbits in all groups for the measurement of superoxide dismutase levels in erythrocyte lysates, using commercially available colorimetric assay kits, and an indirect xanthine-xanthine oxidase method, as described by with the results expressed in $\mathrm{IU} / \mathrm{mL}$.

II. Measurement of the level of TBARS in nucleus accumbens of tested mice as a marker of lipid peroxidation $[16,17]$

Nucleus accumbens of each mouse in each group was excised out of the brain and rinsed with cold $0.14 \mathrm{M} \mathrm{NaCl}$, and part of it was homogenized in $25 \%$ ice cold $50 \mathrm{mM}$ Tris- $\mathrm{HCl}$ buffer, $\mathrm{pH}$ 7.4. One hundred and fifty micro liters of the tissue supernatant of samples was diluted to $500 \mu \mathrm{L}$ with deionized water. A total of $250 \mu \mathrm{L}$ of $1.34 \%$ thiobarbituric acid was added to all the tubes, followed by the addition of an equal volume of $40 \%$ trichloroacetic acid.

The mixture was shaken and incubated for 30 minutes in a boiling water bath. Tubes were allowed to cool to room temperature and the absorbance was read at $532 \mathrm{~nm}$ using zero concentration as blank.

III. Effect of lamotrigine on the activities of nucleus accumbens catalase and glutathione peroxidase of tested mice

a) Catalase enzyme activity [18]

Catalase activity in the nucleus accumbens homogenates was assayed colorimetrically using dichromate-acetic acid reagent (5\% potassium dichromate and glacial acetic acid mixed in a 1:3 ratio). Intensity was measured at $620 \mathrm{~nm}$, and the amount of hydrogen peroxide hydrolyzed was calculated for the catalase activity.

b) Glutathione peroxidase enzyme activity [19]

Glutathione peroxidase activity in the nucleus accumbens homogenates was measured. Activity was expressed based on inhibition of glutathione.

c) Protein determination [20]

The total protein content of nucleus accumbens homogenates was determined. The aim was to express the TBARS concentration as $\mathrm{nmol} / \mathrm{mg}$ tissue protein, and catalase and glutathione peroxidase enzyme activity as Unit/mg tissue protein.

\section{Ethics}

All procedures were in accordance with the National Institute of Health's Guide for the Care and Use of Laboratory Animals, as well as the guidelines of the Animal Welfare Act.

\section{Data analysis}

The results were presented as medians with 25 and 75 percentiles for seizure score and mean \pm standard deviation for seizure onset. Data were analyzed using one-way analysis of variance with Tukey $t$-test at a $95 \%$ confidence level with significant differences between groups at $\mathrm{p}<0.05$.

\section{Results}

\section{A) Effect of lamotrigine on PTX-induced convulsions}

Single dose lamotrigine treatment significantly $(\mathrm{p}<0.05)$ delayed the onset and reduced the severity of PTX-induced convulsions compared with the control groups (1 and 2) (Table 1). 
Citation: Kamal SM (2013) Possible Anti-oxidant Effect of Lamotrigine in Nucleus Accumbens of Mice Exposed to Picrotoxin. J Neurol Disord 1: 108. doi:10.4172/2329-6895.1000108

Page 3 of 5

\begin{tabular}{|l|l|l|l|l|}
\hline Group & $\begin{array}{l}\text { Onset of convulsions } \\
\text { in seconds }\end{array}$ & \multicolumn{3}{|l|}{ Severity ( Score range (1-7) } \\
\cline { 5 - 6 } & $\mathbf{2 5 \%}$ & Median & $\mathbf{7 5 \%}$ \\
\hline $\begin{array}{l}\text { Control without vehicles } \\
\text { group (1) }\end{array}$ & $430.2 \pm 26.67$ & 5 & 5 & $1^{*}$ \\
\hline $\begin{array}{l}\text { Control injected with } \\
\text { vehicles (group 2) }\end{array}$ & $428.9 \pm 17.16$ & 5 & 5 & $1^{*}$ \\
\hline $\begin{array}{l}\text { Group-treated with } \\
\text { lamotrigine dissolved in } \\
\text { vehicles (group 3) }\end{array}$ & $1376 \pm 8484$ & 5 & 5 & $2^{*}$ \\
\hline
\end{tabular}

Notes: Modulation of onset and severity of PTX-induced convulsions in mice treated with lamotrigine (groups 3), Treatment with lamotrigine significantly $(p<0.05)$ delayed onset of convulsions and reduced their severity score compared with the control groups (group 1 and 2)

Table 1: Effect of treatment with lamotrigine on picrotoxin (PTX)-induced convulsions.

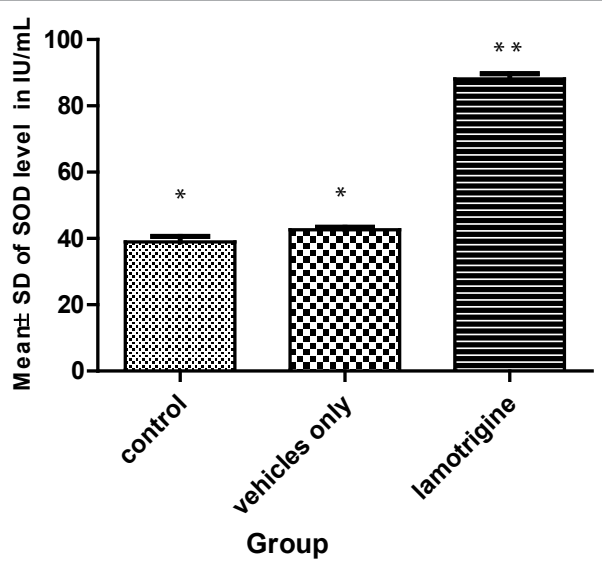

Figure 1: Effect of lamotrigine on superoxide dismutase (SOD) enzyme content in RBCs lysates of tested albino mice.

Exposure to chronic restraint for 21 days of tested mice (Group 1 \& 2) significantly $\left({ }^{*} p<0.05\right)$ reduced superoxide dismutase enzyme content in erythrocyte lysates. However, group (3)-treated with lamotrigine showed significant $\left({ }^{* *} p<0.05\right)$ increase in its content.

B) Anti-oxidant tests after exposure of the three tested groups of mice to chronic restraint model:

\section{Effect of lamotrigine on superoxide dismutase (SOD) enzyme}

Single daily dose of lamotrigine for 21 days, during exposure to chronic restraint, significantly $\left({ }^{*} p<0.05\right)$ increased superoxide dismutase enzyme levels compared to both control groups without and with injection of vehicles $(88.15 \pm 5.6 \mathrm{IU} / \mathrm{mL}$ [Group 3] versus $38.98 \pm 5.8$ and $42.60 \pm 2.7 \mathrm{IU} / \mathrm{mL}$ [Group 1 and 2]) (Figure 1).

Notes: Results are expressed as mean \pm SD ( $\mathrm{n}=12$ mice/group). Lamotrigine-treated group (3) significantly $\left({ }^{*} p<0.05\right)$ increased SOD enzyme levels in comparison to the control groups (1 and 2) exposed to chronic restraint model.

In a pilot study, done before the present study, control group [neither exposed to chronic restraint model nor vehicles or lamotrigine injections], SOD level was approximately close to the value reported with group (3) treated with lamotrigine.

II. Effect of lamotrigine on the level of TBARS in nucleus accumbens of tested mice as a marker of lipid peroxidation

In a pilot study, done before the present study, control group [not exposed to chronic restraint model nor vehicles or lamotrigine injections], TBARS level was approximately close to the value reported with group (3) treated with lamotrigine (Figure 2).

III. Effect of lamotrigine on the activities of nucleus accumbens catalase and glutathione peroxidase

Figure 3 shows changes in the activity of nucleus accumbens catalase in different tested groups of mice.

Figure 4 shows changes in the activity of glutathione peroxidase enzyme in the tested nucleus accumbens of different tested groups of mice.

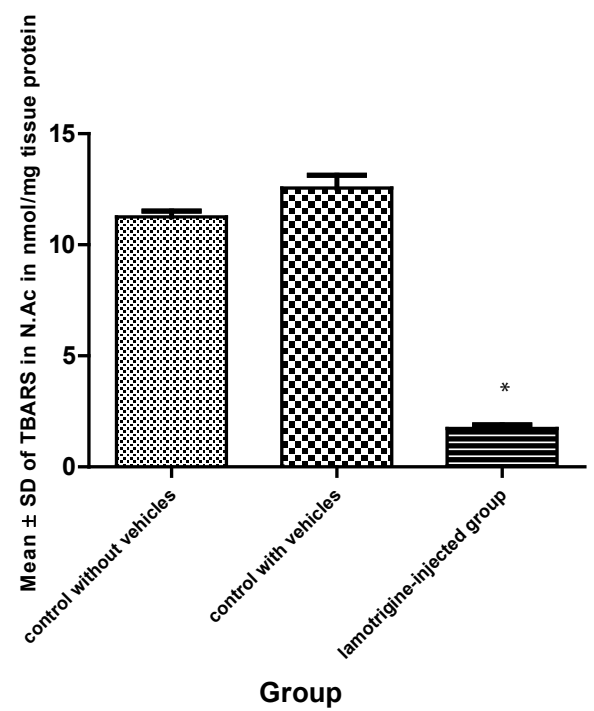

Figure 2: Effect of lamotrigine on the level of TBARS in nucleus accumbens of tested mice as a marker of lipid peroxidation.

Lamotrigine administration to group 3 significantly ( $\left.{ }^{*} p<0.05\right)$ lowered TBARS level compared with the control groups exposed to chronic restraint model (groups 1 and 2).

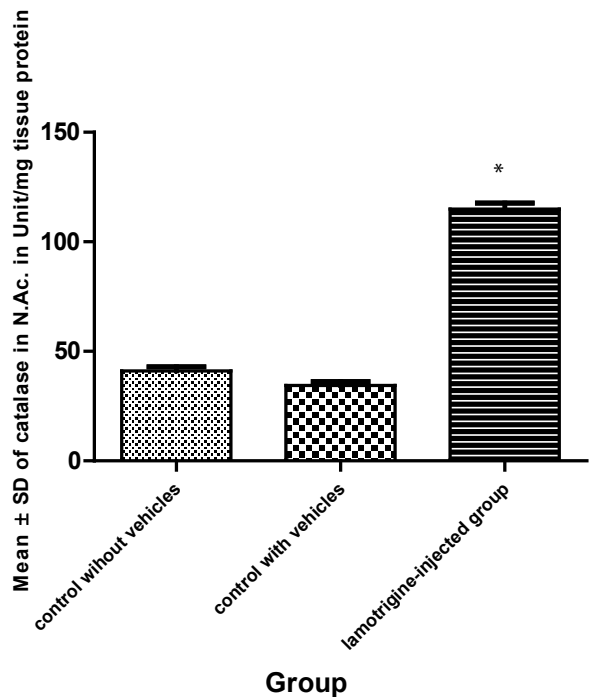

Figure 3: Changes in the activity of nucleus accumbens catalase in different tested groups of mice.

- Significant decrease in the activities of these antioxidant enzymes in groups ( 1 and 2 ) exposed to chronic restraint model.

-While the lamotrigine- treated Group (3) showed that the activities of these enzymes as antioxidants were significantly $\left({ }^{*} p<0.05\right)$ increased compared to control groups (1 and 2).

Changes in the activity of nucleus accumbens catalase in different tested groups of mice. 


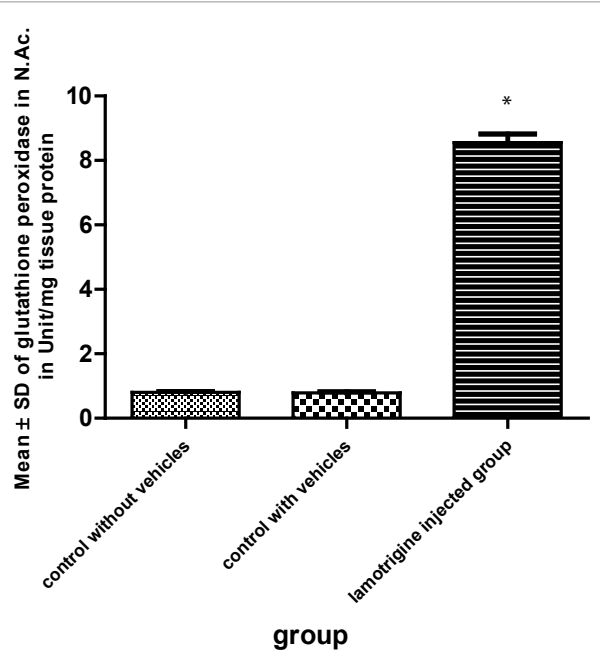

Figure 4: Changes in the activity of glutathione peroxidase enzyme in the tested nucleus accumbens of different tested groups of mice.

There were significant $\left({ }^{*} p<0.05\right)$ increase in activity of both enzymes versus Groups 1 and 2 .

In a pilot study, done before the present study, control group [not exposed to chronic restraint model nor vehicles or lamotrigine injections], activities of both catalase and glutathione peroxidase enzymes were approximately close to the values reported with group (3) treated with lamotrigine.

\section{Discussion}

The oxidative stress and modulation of antioxidant enzyme activity may contribute to the central deleterious consequences of chronic stress. One of the neurochemical complications associated with epilepsy is increased lipid peroxide levels, especially TBARS, in the brain [21,22]. Enhanced lipid peroxidation can induce seizure activity by direct activation of glutamine synthase, thereby permitting an abnormal buildup of the excitatory neurotransmitter glutamic acid [23].

The results of the present study revealed that lamotrigine, as an anti-epileptic drug acts by blocking voltage-dependent sodium channels and inhibiting the release of excitatory amino acids. This may stabilize neurons in epileptic foci, reduced the severity of convulsions and seizure score of picrotoxin-exposed mice. As regards its possible anti-oxidant activity in nucleus accumbens of brains of tested mice exposed to chronic restraint model, the results pointed to a decrease in TBARS content with an increase in the activities of both catalase and glutathione reductase enzymes of this area of pleasure. Lamotrigine also increased the level of superoxide dismutase (SOD) enzyme in erythrocyte lysates of tested mice of the present study.

An experimental study investigated the effects of lamotrigine, aripiprazole and escitalopram administration and experimental depression on lipid peroxidation (LP) and antioxidant levels in cortex of the brain in rats. Depression, as well as the oxidative stress, resulted in significant decrease in the glutathione peroxidase (GSH$\mathrm{Px}$ ) activity, reduced glutathione and vitamin $\mathrm{C}$ of cortex of the brain although their levels and beta-carotene concentrations were increased by the three drugs administrations to the animals of CMS induced depression group. The LP levels in the cortex of the brain and plasma of depression group were elevated although their levels were decreased by the administrations. The increases of antioxidant values in lamotrigine group were higher according to aripiprazole and escitalopram supplemented groups. Vitamin A level did not change in the five groups. In conclusion, the experimental depression is associated with elevated oxidative stress although treatment with lamotrigine has most protective effects on the oxidative stress within three medicines [24].

Blockade of presynaptic release of glutamate by lamotrigine treatment yielded protective effects on the spinal cord ultra structure even when administered after the spinal cord injury (SCI), it also prevented oxidative stress when it was administered before or during the SCI [25].

The effect of carbamazepine and lamotrigine was assessed on cognitive function and oxidative stress in brain during chemically induced epileptogenesis in rats. Epileptogenesis was induced by administration of pentylenetetrazole $(30 \mathrm{mg} / \mathrm{kg}$, s.c.) on alternate days (three times/week) for 9-11 weeks or until stage 4 of seizure score was achieved. The neurobehavioral parameters used for cognitive assessment were step-down latency in continuous avoidance apparatus and transfer latency in elevated plus maze test paradigm. Carbamazepine and lamotrigine were administered intraperitoneally in doses of $60 \mathrm{mg} / \mathrm{kg}$ and $25 \mathrm{mg} / \mathrm{kg}$, respectively, according to the groups, once a day for 11 weeks. Oxidative stress was assessed in isolated homogenized whole brain samples and estimated for the levels of malondialdehyde, reduced glutathione, catalase and superoxide dismutase. The results showed that lamotrigine did not produce any change in cognitive function, while carbamazepine produced cognitive dysfunction. Cognitive decline seen in the carbamazepinetreated pentylenetetrazole-kindled group was also associated with increased oxidative stress. Lamotrigine treatment had no effect on oxidative stress parameters alone, while it significantly decreased oxidative stress in the pentylenetetrazole-kindled group as compared to the pentylenetetrazole-kindled carbamazepine-treated group [26].

In conclusion, the management of epilepsy by lamotrigine could be associated with possible beneficial anti-oxidant actions.

It reduces seizure frequency and intensity in mice exposed to a chemoconvulsive model. Additionally, its anti-convulsant effect could be related to a decrease in levels of the oxidative stress marker TBARS with an increase in catalase and glutathione peroxidase enzymes of nucleus accumbens of brains of tested mice exposed to chronic restraint model.

\section{Acknowledgment}

This research was supported by the Medical Research Service of the Ain Shams University, Cairo, Egypt. It was supported by the Laboratory of the Pharmacology Department, Faculty of Medicine, Ain Shams University, Cairo, Egypt.

\section{Disclosure}

The author reports no conflicts of interest in this work.

\section{References}

1. Friederich M, Hansell P, Palm F (2009) Diabetes, oxidative stress, nitric oxide and mitochondria function. Curr Diabetes Rev 5: 120-144.

2. Johansen JS, Harris AK, Rychly DJ, Ergul A (2005) Oxidative stress and the use of antioxidants in diabetes: linking basic science to clinical practice. Cardiovasc Diabetol 4: 5

3. Obrosova IG (2009) Diabetes and the peripheral nerve. Biochim Biophys Acta 1792: 931-940.

4. Drel VR, Lupachyk S, Shevalye H, Vareniuk I, Xu W, et al. (2010) New therapeutic and biomarker discovery for peripheral diabetic neuropathy: PARP inhibitor, nitrotyrosine, and tumor necrosis factor-\{alpha\}. 
Citation: Kamal SM (2013) Possible Anti-oxidant Effect of Lamotrigine in Nucleus Accumbens of Mice Exposed to Picrotoxin. J Neurol Disord 1: 108. doi:10.4172/2329-6895.1000108

Page 5 of 5

Endocrinology 151: 2547-2555.

5. Fiordaliso F, Leri A, Cesselli D, Limana F, Safai B, et al. (2001) Hyperglycemia activates p53 and p53-regulated genes leading to myocyte cell death. Diabetes 50: 2363-2375.

6. Ziegler D, Rathmann W, Dickhaus T, Meisinger C, Mielck A, et al. (2009) Neuropathic pain in diabetes, prediabetes and normal glucose tolerance: the MONICA/KORA Augsburg Surveys S2 and S3. Pain Med 10: 393-400.

7. Obrosova IG, Drel VR, Oltman CL, Mashtalir N, Tibrewala J, et al. (2007) Role of nitrosative stress in early neuropathy and vascular dysfunction in streptozotocin-diabetic rats. Am J Physiol Endocrinol Metab 293: E16451655.

8. Sudha K, Rao AV, Rao A (2001) Oxidative stress and antioxidants in epilepsy. Clin Chim Acta 303: 19-24.

9. Essman W, Wollman S (1989) Free radicals, central nervous system processes and brain functions. In: Das DK, Essman WB, (eds.). Oxygen radicals: Systemic events and disease processes. Basel Karger.

10. Wang JF, Azzam JE, Young LT (2003) Valproate inhibits oxidative damage to lipid and protein in primary cultured rat cerebrocortical cells. Neuroscience 116: $485-489$

11. Curry WJ, Kulling DL (1998) Newer antiepileptic drugs: gabapentin, lamotrigine, felbamate, topiramate and fosphenytoin. Am Fam Physician 57: 513-520.

12. Schwienbacher I, Fendt M, Richardson R, Schnitzler HU (2004) Temporary inactivation of the nucleus accumbens disrupts acquisition and expression of fear-potentiated startle in rats. Brain Res 1027: 87-93.

13. Li N, He X, Qi X, Zhang Y, He S (2010) The mood stabilizer lamotrigine produces antidepressant behavioral effects in rats: role of brain-derived neurotrophic factor. J Psychopharmacol 24: 1772-1778.

14. Kumar $P$, Kalonia $H$, Kumar $A$ (2012) Possible GABAergic mechanism in the neuroprotective effect of gabapentin and lamotrigine against 3-nitropropionic acid induced neurotoxicity. Eur J Pharmacol 674: 265-274.

15. Halliwell B, Chirico S (1993) Lipid peroxidation: its mechanism, measurement, and significance. Am J Clin Nutr 57: 715S-724S.
16. Benjamins JA, Iwata R, Hazlett J (1978) Kinetics of entry of proteins into the myelin membrane. J Neurochem 31: 1077-1085.

17. Gutteridge JM, Quinlan GJ (1983) Malondialdehyde formation from lipid peroxides in the thiobarbituric acid test: the role of lipid radicals, iron salts, and metal chelators. J Appl Biochem 5: 293-299.

18. Sinha AK (1972) Colorimetric assay of catalase. Anal Biochem 47: 389-394

19. Rotruck JT, Pope AL, Ganther HE, Swanson AB, Hafeman DG, et al. (1973) Selenium: biochemical role as a component of glutathione peroxidase. Science 179: 588-590.

20. Bradford MM (1976) A rapid and sensitive method for the quantitation of microgram quantities of protein utilizing the principle of protein-dye binding. Anal Biochem 72: 248-254

21. Sunanda BS, Shankaranarayana R, Raju TR (2000) Chronic restraint stress impairs acquisition and retention of spatial memory task. Curr. Sci. 79: 15811584.

22. Grillo CA, Piroli GG, Rosell DR, Hoskin EK, Mcewen BS, et al. (2003) Region specific increases in oxidative stress and superoxide dismutase in the hippocampus of diabetic rats subjected to stress. Neuroscience 121 133-140.

23. Scharfman HE, Sollas AL, Berger RE, Goodman JH (2003) Electrophysiological evidence of monosynaptic excitatory transmission between granule cells after seizure-induced mossy fiber sprouting. $J$ Neurophysiol. 90: 2536-2547.

24. Eren I, Naziroglu M, Demirdas A (2007) Protective effects of lamotrigine, aripiprazole and escitalopram on depression-induced oxidative stress in rat brain. Neurochem Res 32: 1188-1195.

25. Tufan K, Oztanir N, Ofluoglu E, Ozogul C, Uzum N, et al. (2008) Ultrastructure protection and attenuation of lipid peroxidation after blockade of presynaptic release of glutamate by lamotrigine in experimental spinal cord injury. Neurosurg Focus 25: E6.

26. Arora T, Mehta AK, Sharma KK, Mediratta PK, Banerjee BD, et al. (2010) Effect of carbamazepine and lamotrigine on cognitive function and oxidative stress in brain during chemical epileptogenesis in rats. Basic Clin Pharmacol Toxicol 106: 372-377. 